\title{
Annotations
}

\section{Choosing investigations}

A paper 'Investigating the small lung: which imaging procedure?' recently appeared in this journal, ${ }^{1}$ written by a radiologist and a clinician. It illustrated the clinico-radiological teamwork we all talk about and seldom practise. Some time age three things were said at a paediatric meeting that still ring in my ears. (1) Ultrasound of the kidney is now so easy and helpful that it is really an extension of the clinical method, to be learnt and done by clinicians. (2) Clinicians are consumers of diagnostic information, radiologists the suppliers. (3) To understand this child's diagnostic problem you need imagination, not science.

\section{Who does what}

Radiologists' hackles naturally rise at the first statement. Sacred territories are being pounced on. Clinicians wielding ultrasound in surgeries, outpatient clinics, or wards: well, they do so already, of course. Cardiologists are involved in much cardiac ultrasound work in this country. The same goes for obstetrics. On the continent-for example Germany -abdominal ultrasound scans are often the preserve of physicians. In Lamarckian fashion, we have grown ourselves excellent accessory organs such as microscopes and stethoscopes: ${ }^{2}$ why cavil at an ultrasound probe for extending clinical perception? Among the very varied reasons for these demarcation disputes, there is the dissatisfied clinician who cannot get his radiologist to understand the needs of his specialty. 'The man's a technician; he can't advise me in my field, and I wish he'd just produce those damned pictures'.

A further argument arises: the living, breathing, cross-sectional anatomy now seen with real-time ultrasound scanners is, well, breathtaking. How can it ever be compressed into a radiologist's report? Is it not his job to supply the best possible images (information) from this magic window, for impartial review by the clinical eye? It is interesting that this argument does not reach into a much older specialty, histopathology. After a biopsy, we expect a pathologist's reasoned report on the likely diagnosis, not a microscope slide. The fences of interpretative difficulty, of separation between living patient and pathological material, seem all too firmly set here. $X$-ray films and scans look much easier and life-like, although there are a lot of them now: from radio- graphs to ultrasound, radionuclide, CT, and NMR images. Clinicians keen to master all these shadows, in best order, have their work cut out.

\section{Data diners and waiters (or: tonight we'll order the CT scan)}

The information transfer between supplier and consumer, supposedly radiologist and clinician, was illustrated in my meeting by a touching picture of two people clasping hands. To some embattled factions this will look falsely rosy. Clinicians occasionally regard radiologists as bloody-minded photographers. They in turn may appear ignorant or profligate to investigative departments. If any handshaking is to be done, both sides might approach with a drawing pin hidden in their palms, just in case. $\mathrm{Oh}$, and with the good of the patient proclaimed by each side.

The new developments can foster two views of radiologists: technique experts or diagnostic consultants. They can now be $x$-ray, ultrasound, CT etc men, stretched across all the clinical fields ploughed by these methods. Or they can be interested in paediatric, uro-, neuro- etc radiology, cutting across all the new techniques at right-angles by clinical specialty. Of course the patient's complaint and his clinician's endeavours inevitably present in this second, clinical orientation. If the radiologist is to speak the same language, to be a consultant's consultant on in vivo imagery, he will have to work in the same direction. An imaging department made up entirely of technique men, however brilliant, is not orientated in the mainstream of the clinical problem. It cannot consult on 'what is best done next'. Choices about its services can only be made by clinicians, sending patients in turn to the ultrasound, CT, or whatever expert. And clinical housemen, registrars, consultants, and practitioners will then have to know an immense amount of radiology, including its press, if they are to choose sensible diagnostic pathways for their patients. I suspect that overinvestigation will be the rule, bad for the patient and the hospital purse.

One trouble is that there are always too many data. Whether the problem is crossing a road, looking at a single $x$-ray film, or choosing the best investigative pathway for a patient, we have to select from the huge available information store. Success is only likely if we choose well. How to be a good judge? I 
am as unsure as anyone, of course, but know that I need imagination and criticism for my attempt, based on learning. And on close acquaintance with what goes on in outpatient clinics, theatres, and on ward rounds as well as inside the four walls of my department.

\section{Scientific method}

Why is science so often confused with the marshalling of endless facts dry as dust? Is the diagnostic work-up really the proud hallmark of scientific medicine, or the unkind, uncritical, and deeply unscientific thing I think it ? ${ }^{3}$ There is probably agreement that the great scientists we all admire were not mindless data collectors. They had ideas, and then performed experiments, direct and elegant, to examine those notions. Like thinking that a sick infant's vomiting and palpable bladder point to lower urinary tract obstruction, and doing a voiding cystogram to see that there are indeed urethral valves? $X$-ray films and scans are at best critical experiments on a well-informed throw of ideas. We could do worse than aiming to be scientists in everyday clinical life. Or: only ask the right questions, and test them by experiment. But what if a child presents with a renal mass thought to be a tumour, what is the next proper experiment? Does the registrar send off forms for IVU, ultrasound, radionuclide, and CT studies, or could he consult the clinical radiologist in the field with the single request 'please sort out'?

There is no room for a silly demarcation dispute, or for data diners and waiters. You do not see them in the best places. You find hybrid beasts linked in a common endeavour. All diagnostic imagery is indeed an extension of the clinical method, with clinician and radiologist very close on each other's heels. For the moment we seem to need clinical radiologists: organising, questioning, advancing, and choosing pictures and pathways rather than merely reporting them. Tomorrow, of course, we may be able to do without them. That is, when those splendid diagnostic tools are always used kindly, economically, and scientifically for all patients, rather than as mindless answering services to ill-chosen or unstated questions. Which is better for the patient?

\section{References}

1 Gordon I, Helms P. Investigating the small lung: which imaging procedure? Arch Dis Child 1982; 57: 696-701.

2 Medawar P B, Medawar J S. The life science. London: Granada/Paladin, 1978.

3 Sherwood T. Science in radiology. Lancet 1978; i: 594-5.

THOMAS SHERWOOD

Department of Radiology, Addenbrooke's Hospital, Hills Road, Cambridge CB2 2QQ 